\title{
LA PUBLICIDAD DE LOS PRINCIPIOS MORALES
}

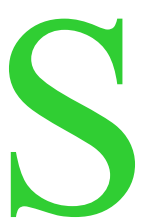

uele ser comúnmente aceptado entre los filósofos que los principios morales deben ser públicos, esto es, que todos sus destinatarios deben ser informados de su contenido. Para entender mejor el fundamento de esta posición tan difundida me parece adecuado emplear una estrategia oblicua y examinar qué es lo que resulta objetable de una moral secreta.

Hay por lo menos tres sentidos en los que se emplea la distinción entre moral pública y moral privada que deben separarse cuidadosamente: a) En un primer sentido, se trata de establecer una línea divisoria entre la vida privada y las responsabilidades públicas, y -si el intento resulta factible- de postular principios morales diferentes para cada una de esas áreas. Esta es la acepción que -por ejemplo- examina el libro de Hampshire ${ }^{1}$. b) En un segundo sentido, la moral pública es concebida como aquella que especifica deberes que se aplican a cualquiera, sin hacer referencia a persona o personas específicas: uno no tiene un conocimiento específico de la persona a la cual se le atribuye el deber. La moral privada, en cambio, es aquella parte del código moral que se refiere necesariamente a persona o personas específicas: son deberes que conciernen a las relaciones entre individuos específicos. En estos términos se estudia el tema -por ejemplo- en el libro de Gauss ${ }^{2}$. c) En un tercer sentido, finalmente, se trata de defender la idea de que ciertos principios morales no deben enunciarse en público, sino mantenerse en secreto, como patrimonio de una élite moral.

${ }^{1}$ Stuart Hampshire (ed.), Public and Private Morality, Cambridge University Press, 1978.

${ }^{2}$ Gerald F. Gauss, Value and Justification, Cambridge University Press. 1990. págs. 322-324. 
Esta es la acepción que reiteradamente critica Rawls. Lo hace, por ejemplo, cuando reivindica la condición de la publicidad de los principios de justicia, que él considera un rasgo propio de las teorías contractualistas, o cuando caracteriza a las instituciones como sistemas públicos de reglas en el que todos los que participan conocen lo que las reglas requieren de él y de los demás ${ }^{3}$.

Voy a concentrarme en examinar el tercero de los sentidos que he mencionado. La secretividad entendida de esta manera no ha sido por cierto patrimonio exclusivo de la moral, puesto que también la ciencia exhibe casos de este tipo. En el siglo V antes de Cristo los pitagóricos defendían por ejemplo el secreto en la ciencia de las matemáticas. Para ellos el número era la clave para encontrar el orden de la naturaleza como un todo. Esta doctrina sufrió un duro golpe cuando se descubrió que ninguna ratio podría describir la relación entre la diagonal de un cuadrado y su lado, lo cual ponía en duda la doctrina de que las cosas eran números ${ }^{4}$. Ante tal contingencia los pitagóricos decidieron mantener secreto su descubrimiento matemático.

En la vinculación de la política con la moral también puede descubrirse un elemento de secretividad. El ejemplo más claro lo proporciona Bernard Mandeville en un trabajo publicado en 1714, impreso adecuadamente como parte de una obra denominada The Fable of the Bees: or Private Vices, Public Benefits. La idea de Mandeville es que fueron los políticos habilidosos los que inculcaron los primeros rudimentos de la moral, y que lo hicieron con el fin -que obviamente mantuvieron secreto- de que los súbditos fueran útiles y tratables, de modo que ellos pudieran gobernar al mayor número de ciudadanos con la mayor seguridad y facilidad posibles. Para lograr tal fin, hicieron creer a la gente que era más beneficioso dominar los apetitos y no satisfacerlos, preferir el bien de los demás y no el propio. Como no era tarea fácil convencer a los individuos de tal cosa, y como los políticos no tenían recursos suficientes como para recompensar realmente a los individuos por esta conducta de auto-privación, concibieron una recompensa imaginaria, elogiando la excelencia de los que así se comportaban, la vastedad de su conocimiento y la racionalidad de sus almas. Fueron tan exitosos en esta tarea que muy pronto los que controlaron sus inclinaciones pudieron advertir que evitaban gran cantidad de dificultades y escapaban 16 y $55-56$.

${ }^{3}$ John Rawls, A Theory of Justice, Cambridge, Mass., Harvard University Press, 1977, págs.

${ }^{4}$ W. K. Guthrie, «Pythagoras and Pythagorteanisms», en The Encyclopedia of Philosophy, Paul Edwards (ed.), London, MacMillan Publishing Co., 1967, volumen 7, pág. 38. 
a menudo a las calamidades que les sucedían a aquellos que eran demasiado ávidos en la persecución de sus placeres.

Se llamó entonces vicio a todo lo que gratificara los apetitos sin consideración a lo público, y virtud a toda actuación contraria a los impulsos de la naturaleza mediante la cual los hombres se esforzaban en beneficiar a los demás y en conquistar sus pasiones. Y todo esto permitía a quienes inculcaban estos principios recoger los frutos del trabajo y de la auto-privación de los demás, y satisfacer sus propios apetitos con menos perturbación. Según Mandeville los hombres no calmaron sus pasiones debido a ninguna religión ni a ninguna superstición idólatra, sino debido al manejo habilidoso de políticos cautos, que mantuvieron secretos sus designios ${ }^{5}$.

Había en este caso, entonces, una moral privada (mantenida en secreto) que defendía el egoísmo y la auto- satisfacción, y una moral pública (que era la que se predicaba) que defendía el altruismo y la auto-privación.

Pero la crítica de Rawls tiene un destinatario más moderno y éste es el utilitarismo. Dentro de la teoría utilitarista, de un modo más específico, la crítica de Rawls se refiere a las ideas de Sidgwick. De modo que voy a dedicarme a explicar la manera de Sidgwick entendió -y defendió- la idea de la secretividad de ciertos principios morales.

En las páginas finales de The Methods of Ethics Sidgwick encara el problema del utilitarismo secreto, sin dedicarle por otra parte al tema más que un par de páginas. Comienza diciendo que desde el punto de vista de los principios utilitaristas podría ser correcto recomendar en privado lo que no sería correcto defender públicamente; podría ser correcto hacer algo si puede ser hecho en secreto, aunque sería incorrecto hacerlo a la vista de todo el mundo ${ }^{6}$. Por supuesto que Sidgwick advierte de inmediato el carácter paradójico de esta idea, teniendo en cuenta que usualmente se considera que si una acción es mala al realizarse abiertamente el secreto no la convierte en buena ${ }^{7}$. Los propios utilitaristas sostienen que aquellos actos que

${ }^{5}$ Bernard Mandeville, «An Inquiry into the Origin of Moral Virtue», en British Moralists 1650-1800, D. D. Raphael (ed.), Oxford, Clarendon Press. 1969, págs. 230 y 232-233.

${ }^{6}$ Henry Sidgwick, The Methods of Ethics, seventh edition, London, MacMillan Co., 1962, pág. 489 .

${ }^{7}$ Conviene aclarar, sin embargo, que esto no ocurre con todas las acciones según la moral del sentido común. Se considera correcta, por ejemplo, mantener relaciones sexuales con el o la cónyuge siempre que esa acción se realice dentro de un comparativo secreto, pero se considera incorrecto realizar esa misma acción en público. 
deben reprimirse mediante la desaprobación social deben ser conocidos, puesto que de otra manera la desaprobación no puede operar. No obstante, Sidgwick resuelve la paradoja aumentando el grado de secreto, esto es, incorporando un secreto de nivel superior. Dice, en efecto, que la opinión misma de que el secreto puede convertir a una acción en correcta debería mantenerse en secreto, y que la doctrina misma de que la moral oculta es expeditiva debería mantenerse oculta.

De modo que nos encontramos con dos niveles de secreto: en el Nivel Uno, la corrección de determinadas acciones se mantiene en secreto, y en el Nivel Dos, la doctrina que sostiene que hay acciones que son correctas si se realizan en secreto se mantiene a su vez secreta. Hay un secreto y un metasecreto: algunos principios se mantienen secretos y el hecho de que ese secreto es bueno también se mantiene secreto. El secreto sólo desaparecería, piensa Sidgwick, si viviéramos en una comunidad ideal de utilitaristas ilustrados ${ }^{8}$.

Veamos primero el Nivel Uno, el nivel del secreto de algunos principios morales. Puede haber aquí dos posibilidades: a) se mantiene secreto el hecho de que un cierto $\mathrm{x}$ es un medio para conseguir la felicidad, y b) se mantiene secreto que debe perseguirse la felicidad como fin. (Asumo que la felicidad es el fin que debe perseguirse, puesto que Sidgwick considera el tema del secreto moral únicamente en relación a la teoría ética utilitarista). Puede haber entonces un secreto de medio o un secreto de fines. Pero no me parece que pueda haber -a la vez- ambos secretos. En otras palabras: creo que hay un límite a la secretividad de los principios morales en el Nivel Uno, que voy a mostrar en los ejemplos que siguen.

El caso del padre responsable (versión uno): Pedro

es un padre responsable y quiere que su hijo Pedrito

engorde porque esto es bueno para su salud. Pero

Pedrito siempre se opone a los planes de Pedro, por lo que éste no le dice que es bueno tener buena salud. Aunque sabe que engordar es un medio para tener buena salud, Pedrito engorda porque le mantuvieron en secreto la bondad del fin.

El caso del padre responsable (versión dos):

Con el mismo propósito que en el caso anterior Pedro

le revela a Pedrito que es bueno tener buena salud pero le oculta que engordar es un buen medio

${ }^{8}$ Sidgwick, cit., pág. 490. 
para ello. Igual que en la versión anterior,

Pedrito engorda porque le mantuvieron en secreto

la bondad del medio?.

Adviértase un detalle importante que es común a los dos ejemplos anteriores: en ambos el hijo deseaba frustar los deseos del padre a su respecto, y éste era el motivo del ocultamiento por parte del padre. En el primer caso se le ocultaba el fin, y en el segundo se le ocultaba el medio. Con cualquiera de los dos ocultamientos el padre conseguía su propósito, esto es, que su hijo engordara. Puesto que Sidgwick mismo no considera al secreto como un rasgo elogiable de una teoría moral ${ }^{10}$ creo que podemos asumir sin riesgo que una teoría moral será mejor cuanto menos secreto tenga. En consecuencia, si se puede obtener el fin deseado con el menor secreto posible, lo correcto es hacerlo así. Los ejemplos anteriores nos permiten entonces establecer el límite de la secretividad de los principios morales: si se mantiene en secreto el fin no es necesario mantener en secreto los medios, y si se mantienen en secreto los medios no es necesario mantener en secreto el fin. Y puesto que hemos visto que una teoría moral mejora cuando disminuye su grado de secreto, el hecho de que un nivel de secreto no sea necesario muestra que ese nivel es incorrecto.

Traslademos ahora los ejemplos anteriores a la propuesta de Sidgwick. En el primer caso, habría que ocultarle a ciertos individuos que la felicidad es el fin que debe alcanzarse. En el segundo caso, a su vez, habría que ocultarle a ciertos individuos que ciertos medios conducen a la felicidad. Esta circunstancia plantea un problema que estaba ausente en los ejemplos citados. En ellos, Pedro era un padre responsable y Pedrito un hijo menor de edad que ignoraba lo que le convenía. El paternalismo de Pedro, entonces, era un paternalismo elogiable, el de un padre que se preocupa por el bienestar de sus hijos menores, aún en contra de la voluntad de éstos ${ }^{11}$. Pero Sidgwick propone otra cosa: propone que tratemos a ciertos adultos como si fueran niños y los hagamos felices aún en contra de su voluntad. Este es el paternalismo que han criticado todos los partidarios de la autonomía, en especial a partir de la aparición de la

${ }^{9}$ Conviene aclarar que en ambos casos el «porqué» se emplea con el alcance de condición necesaria, pero no de condición suficiente.

${ }^{10} \mathrm{Si}$ el utilitarismo requiere en ciertas circunstancias algún grado de secreto y Sidgwick no considera al secreto un rasgo elogiable en una teoría moral, es obvio que en este aspecto esté empleando criterios independientes del utilitarismo.

${ }^{11}$ Quiero aclarar que hay un sentido en el cual Pedro no actúa «en contra de la voluntad» de Pedrito. Al haber sido engañado, Pedrito actúa voluntariamente. Su voluntad está viciada, como se dice el uso ordinario, pero no puede afirmarse que no exista. Si el objeto de la voluntad es un hecho, Pedrito actúa voluntariamente. 
tesis de Mill en On Liberty. Supongamos que un adulto es partidario del principio del ascetismo, tal como lo describía Bentham ${ }^{12}$ : una acción es correcta en tanto tiende a disminuir la felicidad, e incorrecta en tanto tiende a aumentarla. Este principio se opone entonces de manera constante al principio utilitarista. ¿Estamos autorizados moralmente a obligar a ese individuo a ser feliz? ¿Podemos hacerlo feliz utilizando la técnica del secreto en la forma propuesta por Sidgwick? Como se aprecia con claridad, la tesis de Sidgwick enfrenta un problema que estaba ausente en los ejemplos del padre responsable: el problema de la variedad criticable del paternalismo, no del paternalismo del padre que trata de esa forma a sus hijos menores, sino de los individuos que tratan a otros adultos con los que no tienen relación de parentesco como si ellos fueran sus hijos menores.

El utilitarismo -por supuesto- no tiene por qué oponerse al paternalismo. Si el único fin que es tenido en cuenta es la felicidad, y el criterio de correlación de las acciones deriva del grado en que ellas promueven la felicidad general, no se sigue de esto que la autonomía de los individuos deba ser respetada en el caso de que su violación incremente la felicidad general. Pero el utilitarismo ha tratado siempre de mostrar que su teoría es compatible con los principios liberales: no es casualidad que On Liberty haya sido escrito por uno de los más famosos teóricos del utilitarismo. En este sentido, el paternalismo implícito en la tesis de Sidgwick constituye una dificultad para la teoría utilitarista. Volveré sobre este tema enseguida al ocuparme del otro nivel de la secretividad y explicaré allí el particular defecto moral del paternalismo mantenido en secreto.

Veamos ahora entonces el Nivel Dos, esto es, el nivel en el cual se mantiene secreto el hecho de que es bueno practicar el secreto en el Nivel Uno. Para ello, examinemos nuevamente

El caso del padre responsable (versión tres):

Pedro quiere que Pedrito engorde y le prepara

una dieta estricta. A veces sería mejor apartarse

de ella, pero Pedro cree que Pedrito no tiene

discernimiento como para hacerlo y le mantiene

en secreto las características de esos casos, y

la existencia misma de la posibilidad de apartarse

de la dieta.

Lo que diferencia a este caso de las versiones anteriores es que aquí Pedro y Pedrito coinciden en cuanto al fin: ambos quieren que

12 Jeremy Bentham, An Introduction to the Principles of Morals and Legislation, Oxford, Basil Blackwell, 1967, págs. 132-133. 
Pedrito engorde. Si no fuera así estaríamos en la versión 1 o en la versión 2 de este caso. Aquí se mantiene el secreto en el Nivel Uno (Pedrito no sabe cuáles son los casos en los que convendría apartarse de la dieta) y en el Nivel Dos (Pedrito no sabe que hay casos en los que conviene apartarse de la dieta). Trasladado al plano en que Sidgwick defiende el Nivel Dos de secreto, a los individuos se les oculta dos cosas: a) cuáles son los casos en los que conviene apartarse de las reglas, y b) que es posible apartarse de las reglas. ¿Es éste un ejemplo de paternalismo? Depende. Aunque coincida con su padre respecto del fin, si Pedrito quiere decidir por sí mismo y el padre se lo impide con sus niveles de secreto, sí lo sería. Y el paternalismo aceptable en el caso de Pedro y de Pedrito sería inaceptable en el caso avizorado por Sidgwick. La única manera de evitar la acusación de paternalismo consistiría en mostrar que los individuos a quienes se mantiene en la ignorancia han manifestado claramente su confianza absoluta en el grupo que los dirige y le han pedido a ese grupo que se limite a darles las instrucciones que sean convenientes para incrementar la felicidad general. Un ejemplo real no es difícil de imaginar. Supongamos que un paciente adulto le diga a su médico: -«Yo confío en su capacidad profesional para curarme. Dígame el tratamiento que debo seguir, pero mantenga en secreto tanto el diagnóstico cuanto las eventuales ventajas que podrían seguirse de un eventual apartamiento de sus instrucciones en ciertos casos». Si el médico atiende al pedido de su paciente no puede decirse que se comporte de manera paternalista.

Pero el problema aparece, por supuesto, cuando Pedrito -tal como ocurría en las versiones 1 y 2- no comparte los fines de Pedro. Cuando, en el caso de Sidgwck, hay individuos que no desean contribuir a la felicidad general ${ }^{13}$. En esta circunstancia reaparece el paternalismo objetable y no hay manera de reconciliar la idea utilitarista de Sidgwick con la tesis liberal. Esto no debe sorprendernos. Cuando Sidgwick ${ }^{14}$ estudia el principio de que un individuo no debería ser coercionado sólo por su propio bien señala que nadie afirma que este principio debe aplicarse a los niños, a los idiotas o a los locos. Pero si esto es así, pregunta, ¿podemos conocer a priori que debe aplicarse a todos los adultos sanos? Y responde: no es intuitivamente cierto que el mismo argumento no se aplique a la mayoría de la humanidad en su estado presente de progreso intelectual.

${ }^{13} \mathrm{O}$ cuando desean contribuir a la felicidad general, pero no tienen confianza absoluta en el grupo dirigente, de modo que no aceptan ser mantenidos en la ignorancia.

${ }^{14}$ Sidgwick, cit., pág. 275. 
Sidgwick no permitía ciertamente que su utilitarismo fuera limitado por consideraciones liberales.

¿Hay algún límite a la secretividad en el Nivel Dos que se corresponda con el límite que aparecía en el Nivel Uno? En el Nivel Dos se mantiene en secreto la posibilidad misma de mejorar la dieta por parte de Pedrito, y no ya los casos en los cuales esta mejoría podría operar. No hay que buscar un límite en este caso; hay en cambio una implicación que vincula a ambos niveles de secreto: el secreto en el Nivel Dos implica el secreto en el Nivel Uno. En efecto: mantener en secreto que la dieta tiene la posibilidad de ser mejorada implica mantener en secreto los casos específicos de mejoría de la dieta. En cambio, el secreto en el Nivel Uno no implica el secreto en el Nivel Dos. Pedro podría decirle a Pedrito: -«No es ningún secreto que la dieta puede ser mejorada en ciertos casos, pero voy a mantener esos casos en secreto».

¿Qué es lo que busca Sidgwick con la introducción del utilitarismo secreto? A mi parecer, busca algo curioso: defender al utilitarismo de reglas. Supongamos que exista una regla cuyo cumplimiento asegure la promoción de la felicidad general. Sin embargo, en ciertos casos concretos un apartamiento de la regla provocaría un aumento mayor en la felicidad general que el que provocaría su obediencia. Claro que no todos los individuos están capacitados para detectar esos casos concretos, por lo que la felicidad general se promoverá más efectivamente si mantenemos en secreto la existencia de tales casos, y aún la posibilidad misma de apartarse de las reglas.

Pero, ¿qué tiene esto de curioso, si es -en apariencia- una defensa bastante usual del utilitarismo de reglas, con el único agregado del recurso del secreto? La curiosidad deriva de la circunstancia de que Sidgwick es un fervoroso defensor del utilitarismo de actos. Cuando percibimos que los efectos de una tendencia felicífica son contrarios a la felicidad en un caso particular, dice Sidgwick, condenamos la tendencia en la medida en que opera de ese modo, y si se la sigue igualmente hablamos de fanatismo ${ }^{15}$. En otras palabras: seguir una regla en los casos en los que apartarse de ella maximiza la felicidad general es cosa de fanáticos. Pero el problema de Sidgwick parece consistir en averiguar cuáles son las personas capacitadas para apartarse de las reglas. (Sin embargo, también puede interpretarse el intento de Sidgwick como una política de promoción de las reglas y no como una defensa teórica de la superioridad del utilitarismo de reglas. Al admitir que se puede promover mejor

${ }^{15}$ Sidgwick, cit., pág. 428. 
la felicidad general apartándose a veces de las reglas Sidgwick estaría defendiendo en realidad al utilitarismo de actos, si bien limitado a un cierto grupo de individuos. Esta interpretación tiene la ventaja de armonizar con el resto de la teoría utilitarista de Sidgwick).

Esto es precisamente lo que tiene de moralmente objetable la idea del secreto. No es lo único objetable, por cierto, y no es esta la tesis que defiendo. Gibbard, por ejemplo, muestra dos defectos importantes de la secretividad. El primero de ellos resulta de la circunstancia de que hablar de un modo insincero tiene un costo sicológico, puesto que priva al individuo que así lo hace de ciertas recompensas emocionales. El segundo radica en el hecho de que la falta de sinceridad afecta el propio juicio del individuo, puesto que el diálogo sincero contribuye a pensar correctamente ${ }^{16}$. Y Brandt comparte plenamente la crítica de Gibbard ${ }^{17}$. Pero el principal defecto, como acabo de señalar, radica en que la secretividad rechaza la igualdad moral de los individuos y sostiene la existencia de una elite. La elite está capacitada para apartarse de las reglas, pero el resto de los individuos no debe conocer siquiera esta posibilidad. La elite, por supuesto, consiste en el grupo de utilitaristas ilustrados de que habla Sidgwick. Esto es lo que resulta objetable si se acepta la idea de la igualdad. Y sigue siendo objetable aunque los utilitaristas ilustrados puedan hablar entre ellos con total sinceridad y sin padecer ninguno de los costos que señalaban Gibbard y Brandt. Es cierto que podría afirmarse que la igualdad moral no resulta afectada en estos casos porque la felicidad de todos los individuos cuenta por igual. Habría sólo una desigualdad fáctica, porque de hecho la generalización de ciertos conocimientos resultaría paretianamente ineficiente. Esta afirmación, sin embargo, no me resulta convincente puesto que la igualdad moral incluye la dignidad igual de todos los agentes morales, y negar que una persona posea la capacidad suficiente como para poner en práctica los principios morales significa privarla de su dignidad, aunque sea en forma parcial.

Pero, podría argumentarse, si la principal objeción a la secretividad reside en su aspecto paternalista, ésta no es una objeción específica al secreto. Porque el utilitarismo, secreto o no secreto, puede ser paternalista en la medida en que adoptar ese recurso maximice la felicidad general. Esto es cierto, desde luego. Sin embargo, hay algo particularmente objetable en la adopción del secreto. En este

${ }^{16}$ Allan Gibbard, «Utilitarianism and Human Rights», Social Philosophy and Policy, Vol. 1, Issue 2, pág. 101.

${ }^{17}$ Richard B. Brandt, Morality. Utilitarianism, and Rights, Cambridge University Press, 1992, pág. 206. 
caso no sólo se emplean recursos paternalistas, sino que las «víctimas» del paternalismo ignoran incluso su carácter de tales. Al no tener conciencia de que son «víctimas» del paternalismo les resulta entonces más difícil rebelarse y procurar la restitución de su autonomía. Supongamos que en una sociedad determinada la elite dominante le niegue públicamente a sus súbditos la posibilidad del voto como medio de adoptar decisiones; las decisiones quedan circunscriptas a la elite. Los súbditos saben, entonces, que están privados de decidir por sí mismos y pueden luchar para remediar esta situación, la que -entre otras cosas- socava su autorrespeto. Pero supongamos ahora que esa misma elite mantiene oculta la circunstancia de que es posible votar para adoptar decisiones, diciéndole a los súbditos -por ejemplo- que Dios ha colocado en las manos de la elite la facultad de decidir. Este segundo tipo de paternalismo es peor que el primero, porque no sólo vulnera la autonomía de los individuos, sino que ni siquiera les informa que está vulnerando su autonomía. Es este rasgo el que, a mi juicio, toma particularmente objetable el tipo de paternalismo que proviene del secreto respecto de ciertos principios morales. El utilitarismo secreto contraría de manera especial el ideal liberal de la autonomía. (Acepto, sí, que lo contraría con un menor costo de felicidad, puesto que los individuos privados de autonomía no conocen esta circunstancia. Para condenar al utilitarismo secreto, entonces, hay que sostener la idea de la preeminencia absoluta de la autonomía sobre la felicidad).

Es este aspecto particularmente objetable de la secretividad el que pasa por alto la crítica de Bemard Williams a las ideas de Sidgwick. Williams -con toda razón- identifica la secretividad con una actitud colonialista y denomina irónicamente a la teoría que la emplea el «utilitarismo de la Casa de Gobierno», donde la elite ordena y los súbditos se limita a obedecer $^{18}$. De modo que él considera al paternalismo como el defecto central de la secretividad, pero sin advertir dos cosas: a) que el paternalismo no es un defecto confinado al utilitarismo secreto, pues también puede aceptarlo el utilitarismo público, y b) que el paternalismo mantenido en secreto es aún más objetable que el paternalismo hecho público.

Es, pues, perfectamente legítimo hablar de grados de paternalismo (estoy pensando sólo en el paternalismo objetable y no en la relación de los padres con sus hijos menores), tolerándolo hasta un cierto nivel y rechazándolo en un nivel superior. Es posible, por ejemplo, aceptar el grado de paternalismo que conlleva el utilitarismo

${ }^{18}$ Bernard Williams, Ethics and the Limits of Philosophy, London, Fontana Press, 1985, págs. 108-109. 
público, donde la felicidad general prima sobre la autonomía del individuo, pero a sabiendas de todos. Y rechazar, sin embargo, el grado mayor de paternalismo que conlleva el utilitarismo secreto, donde no sólo la felicidad general prima sobre la autonomía del individuo, sino que ni siquiera los individuos privados de su autonomía conocen la realidad de su situación. (Sobre la base -vuelvo a insistir- de que la autonomía se valora más que la felicidad).

Los problemas derivados de la teoría del utilitarismo secreto no concluyen por cierto aquí. Tampoco se sabe -por ejemplo- cuándo finalizaría la situación de secreto. Sigdwick afirma que todo utilitarista ilustrado debe desear que los restantes miembros de la sociedad concluyan integrando la elite, pero que la distinción entre ilustrados y no ilustrados es «un mal necesario en la situación actual de las comunidades civilizadas» ${ }^{19}$. Además del cuándo también se ignora el cómo. En efecto: si los postulados utilitaristas se mantienen secretos, ¿cómo haríamos para convertir a todos los individuos no ilustrados al utilitarismo?

Claro está que el secreto puede a veces ser aceptado por todos, como he dicho antes. En la versión 3 de El caso del padre responsable Pedrito, cuyos fines -no olvidemoscoinciden con los de Pedro, puede acordar con su padre que se mantengan en secreto determinados aspectos relacionados con su dieta, simplemente para no tentarse. Este no sería entonces un caso de paternalismo. Sus rasgos revelan un parecido con la situación de Ulises y las sirenas y, por tanto, la conducta de Pedro no sería más objetable que la conducta de los marineros que se negaron a liberar a Ulises.

Sidgwick tiene todavía una afirmación paradójica más para proporcionarnos: si el secreto y el meta-secreto son difíciles de mantener, entonces sería deseable para los utilitaristas (ilustrados) que la mayoría de los individuos (no ilustrados) repudiara los postulados del utilitarismo ${ }^{20}$. ¿Cómo debe entenderse esta afirmación? La manera más razonable de interpretarla consiste en sostener que aquellos que se equivocan cuando persiguen directamente la felicidad no deberían entonces hacerlo. Como ha mostrado Parfit ${ }^{21}$ a veces la persecución directa de un fin resulta autofrustrante. Los individuos en cuestión seguirían adhiriendo al fin utilitarista (la maximización de la felicidad), pero los medios para lograrla quedarían circunscriptos a la elite, a aquellos individuos ilustrados que

${ }^{19}$ Sidgwick, cit., pág. 490.

${ }^{20}$ Sidgwick, cit., pág. 490.

${ }^{21}$ Derek Parfit, Reasons and Persons, Oxford, Clarendon Press, 1984 especialmente capítulos 1 y 4 . 
no se equivocan ${ }^{22}$. De este modo, todos los individuos conseguirían más felicidad, que es el fin que todos ellos comparten. En esta interpretación puede haber o no paternalismo según se tome o no en cuenta la voluntad de los individuos que no pertenecen a la elite. Si ellos coinciden en que los utilitaristas ilustrados son más capaces de proporcionarles felicidad y les confían la elección de los medios para hacerlo, entonces no hay paternalismo. (Mi médico y yo coincidimos en el fin de que yo tenga la mejor salud posible. Yo creo que él conoce mejor que yo los medios para lograr ese fin y acepto obedecer sus instrucciones. Mi médico no obra conmigo de manera paternalista). Pero si la elite impone coercitivamente la elección de los medios, entonces se configura una situación paternalista. (Mejor desde el punto de vista moral -de todos modos- que la situación del secreto, porque ahora el paternalismo es conocido por todos).

Parfit está pensando en esta situación: un grupo de individuos que cree que la mejor teoría moral es aquella que produce las mejores consecuencias llega a la conclusión de que las consecuencias mismas serían aún mejores si ellos lograran creer en alguna variedad de la teoría moral del sentido común, y consiguieran tener éxito en su intento: terminarían entonces creyendo en la moral del sentido común. Pero se presenta un grave problema posterior: debido a ciertos cambios en el mundo, las consecuencias podrían mejorar si se revisaran nuevamente las creencias morales del grupo. Sin embargo, ¿cómo van a revisar ahora estos individuos sus creencias morales sobre la base de que se producirían mejores consecuencias en el caso de que lo hicieran si ellos ya no creen en la teoría que recomienda producir las mejores consecuencias, sino en la teoría moral del sentido común? Para evitar este resultado, Parfit sugiere una medida de precaución: unas pocas personas deberían continuar creyendo (en secreto) en la teoría primitiva, y producir evidencia en su favor en caso de que ella fuera necesaria para continuar produciendo las mejores consecuencias en el futuro ${ }^{23}$. Esta sugerencia no conlleva el defecto del paternalismo, puesto que está implícita la idea de que todos los individuos que aceptan cambiar sus creencias en la teoría primitiva -precisamente para conseguir mejor los resultados que ella se propone- están también de acuerdo en que algunos continúen creyendo en ella en secreto.

Dejando a un lado ahora las dificultades derivadas del paternalismo, queda por examinar un solo tema vinculado con el secreto de

${ }^{22}$ De otra manera de interpretar la afirmación de Parfit, por supuesto, es que la mayoría de los individuos debería ignorar la idea misma de que el fin que debe perseguirse es la felicidad.

${ }^{23}$ Parfit, cit., págs. 41-42. 
los principios morales y es el de su relación con la neutralidad y la relatividad agencial. Dos palabras primero acerca de la terminología que voy a emplear respecto de este tema, introducido originariamente por Thomas Nagel y desarrollado luego por Parfit.

Cuando hablo de «razón» estoy pensando en algo que se utiliza como justificación o como fundamento. Una razón agencialmente neutral nos dice que debemos buscar imparcialmente la felicidad general (o, si no queremos vincular de una manera tan decidida la neutralidad agencial con el utilitarismo, nos dice que debemos buscar imparcialmente el bien intrínseco). Las razones agencialmente neutrales no son simplemente razones que todos tienen. Es posible que exista una razón para que todos los individuos puedan ocuparse especialmente de sus propios hijos, aunque esta conducta disminuya la felicidad general. Esta es una razón general, sin duda, porque todos la tienen, pero no una razón neutral, porque permite dejar de lado la felicidad general. La neutralidad agencial, en resumen, prescribe la consideración imparcial de la felicidad de todos los individuos.

Las razones agencialmente relativas, a su vez, son de dos tipos: razones de autonomía y razones deontológicas. Las razones agencialmente relativas de autonomía permiten dejar de lado la felicidad general en ciertos casos, cuando ello es necesario para desarrollar el plan de vida del agente. Las razones deontológicas, en cambio, obligan a dejar de lado la felicidad general en ciertos casos (ordenan no matar, por ejemplo, ni siquiera cuando matando se disminuye el número de muertes).

Las razones, tanto neutrales como relativas, sirven como fundamento de normas. Pero del simple contenido de una norma no puede inferirse si ella está fundada en una razón neutral o en una razón relativa. Supongamos que una norma nos permita salvar a un pariente con preferencia respecto de las demás personas. En apariencia, estamos aquí ante una norma fundada en una razón agencialmente relativa. Pero no es necesariamente así, por supuesto. Consideremos el caso del individuo que debe optar entre salvar la vida de Fenelón o de su criado, sobre la base de que el mérito de Fenelón es muy superior al del criado, pero el criado -a su vez- es el padre del salvador que debe optar entre ambos. Este es el caso que analiza William Godwin, llegando a la conclusión de que permitir salvar al padre estimula un hábito que ocasionará una serie sucesiva de utilidades futuras, de donde resultará en beneficio de la felicidad general ${ }^{24}$. Es

${ }^{24}$ William Godwin, «Toughts Occasions by the Perusal of Dr. Parr's Spital Sermon, Preached at Christ Church, April 15, 1800", en Enquiry Concerning Political Justice, Oxford, Clarendon Press, 1971, pág. 325. 
así que una norma que permita tomar en consideración relaciones de parentesco puede ser una norma instrumental, en el sentido de estar basada en una razón agencialmente neutral y ser el medio de maximizar la felicidad general. Por supuesto, que no cabe excluir la posibilidad de que esa misma norma esté basada en una razón agencialmente relativa y que se permita tomar en consideración a las relaciones de parentesco, aunque la felicidad general disminuya. Pero para averiguar esto no podemos detenemos en el contenido de la norma.

¿En qué tipo de razones estaba pensando Sidgwick cuando introdujo el tema del utilitarismo secreto? A primera vista, parece claro que los ciudadanos comunes y los utilitaristas ilustrados deben estar gobernados por normas diferentes. Las normas que guían a los ciudadanos comunes no hacen referencia a la felicidad general, mientras que las normas que guían a los utilitaristas ilustrados, por supuesto que hacen referencia a la felicidad general. No se trata, entonces, en ninguno de los dos casos, de normas generales, puesto que no son normas que valen para todos. Pero ya hemos visto que no había que confundir la generalidad con la neutralidad. Ahora podemos agregar algo más: tampoco hay que confundir la ausencia de generalidad con la ausencia de neutralidad. Porque si bien las normas que guían la conducta de los ciudadanos comunes y de los utilitaristas ilustrados son distintas, la razón que fundamenta estas normas es la misma: es la razón agencialmente neutral de que debe promoverse la felicidad general.

La diferencia en las normas se explica muy sencillamente. En el caso de los ciudadanos comunes se trata de normas instrumentales: sin mencionar a la felicidad general son medios aptos para conseguirla. En el caso de los utilitaristas ilustrados el contenido mismo de la norma ya menciona la felicidad general. Pero en los dos casos el fundamento es el mismo: la razón agencialmente neutral de promover la felicidad general.

Es en este sentido Sidgwick sigue la ortodoxia utilitarista de basarse sólo en razones agencialmente neutrales. Nótese, en especial, que el utilitarismo no acepta que disminuya la felicidad general para que puedan llevarse a cabo determinados planes de vida. Si el utilitarismo quisiera acercarse al liberalismo debería aceptar -en cierta medida- la existencia de razones agencialmente relativas de autonomía. Pero el utilitarismo estricto quiere maximizar la felicidad, no la autonomía.

Resumo, entonces, las conclusiones de este trabajo:

1. Hay dos niveles de secreto en la teoría del utilitarismo secreto. En el Nivel Uno, la corrección de determinadas acciones se mantiene en secreto, y en el Nivel Dos la doctrina que sostiene que 
hay acciones que son correctas si se realizan en secreto se mantiene -a su vez- secreta.

2. Hay un límite a la secretividad en el Nivel Uno: si se mantiene en secreto el fin no es necesario mantener en secreto los medios para alcanzarlo, y viceversa.

3. Hay una implicación en la secretividad que vincula a ambos niveles: el secreto en el Nivel Dos implica el secreto en el Nivel Uno, pero no a la inversa.

4. El paternalismo secreto es particularmente objetable desde el punto de vista moral, puesto que sus víctimas ignoran el carácter de tales.

5. Hay grados de paternalismo, y aunque se acepte el paternalismo que eventualmente puede aparecer en el utilitarismo público, igualmente puede rechazarse el paternalismo que aparece en el utilitarismo secreto.

6. El utilitarismo secreto emplea sólo razones agencialmente neutrales, exactamente como lo hace el utilitarismo público.

Las conclusiones cuarta y quinta muestran que la estrategia oblicua que anunciara al comienzo ha dado algún fruto. Lo objetable de los principios morales secretos habla en favor de la publicidad de tales principios ${ }^{25}$.

${ }^{25}$ Agradezco a Hugo Zuleta sus valiosas observaciones sobre este trabajo. 
DOXA-14 (1993)

$\triangle$ 